\title{
A correlation study of cervical cytology on Pap smear with cervical biopsy in a tertiary hospital of Eastern Nepal
}

\author{
Nirajan Mainali ${ }^{1}$, Neha Homagai ${ }^{2}$, Niraj Nepal ${ }^{1}$, Prabesh Choudhary ${ }^{1}$ \\ ${ }^{\prime}$ Department of pathology, Nobel medical college teaching hospital, Biratnagar, Nepal \\ ${ }^{2}$ Department of Obstetrics and Gynecology, Nobel medical college teaching hospital, Biratnagar, Nepal.
}

\section{Keywords:}

Carcinoma; Cervical biopsy;

Dysplasia; High grade; Low grade; Pap smears;

\begin{abstract}
Background: Carcinoma cervix is among a curable cancer, if identified at an early stage. Pap smear is a simple, safe, noninvasive, outdoor and effective method for detection of lesions of the cervix but it fails to localize the lesion. Cervical biopsy, on the other hand is a gold standard but invasive technique.

Materials and Methods: A prospective cross-sectional study was done in Nobel medical college from January 16, 2017 to January 15, 2018 where all pap smears received in a Department of Pathology were included in the study. However, only cases that had undergone both Pap smear and cervical biopsy were compared. Out of the 1492 pap smears, 118 cases underwent biopsy. Correlation was then done regarding cytological and histological diagnosis.

Results: Majority of the cytological findings were normal. 7 patients of HSIL revealed moderate dysplasia and higher lesions in biopsy. 2 cases were that of adenocarcinoma which were diagnosed as inflammatory smear in Pap smear.

Conclusion: Cervical Pap smear is reliable screening test to identify high grade squamous cell lesions and carcinoma, but it fails to localize the lesion and adenocarcinoma is hard to identify in a pap smear. Hence, cervical biopsy should be carried out to confirm the findings of Pap smear and in case of strong clinical suspicion.
\end{abstract}

\section{Correspondence:}

Dr. Nirajan Mainali, MBBS, MD

Assistant Professor, Pathology

Nobel Medical College Teaching Hospital

Email: mainali_nirajan@hotmail.com

Orcid ID: 0000-0002-6648-1914

Reveived : April 20 2018 ; Accepted :July 21 ${ }^{\text {st }} 2018$; Published : September $1^{\text {st }} 2018$

Citation: Mainali N, Homagai N, Nepal N, Choudhary P. A correlation study of cervical cytology on Pap smear with cervical biopsy in a tertiary hospital of Eastern Nepal. J Pathol Nep 2018;8:1389-92. DOI: $10.3126 /$ jpn.v\%vi\%i.20993

Copyright: This is an open-access article distributed under the terms of the Creative Commons Attribution 4.0 International License, which permits unrestricted use, distribution, and reproduction in any medium, provided the original author and source are credited.

\section{INTRODUCTION}

Cervical carcinoma is one of the most common carcinoma and is a significant cause of mortality around the world. ${ }^{1}$ Factors like lack of effective screening programs, lack of resources and poorly organized health system are among the important reasons for high incidence of cervical cancer in developing countries. ${ }^{2}$ Carcinoma cervix is among a curable cancer, if identified at an early stage. ${ }^{3}$ Transformation zone of the cervix is identified as a startup point for neoplasia of cervix. Pap smear is a simple, safe, noninvasive, outdoor and effective method for detection of lesions of the cervix. ${ }^{4}$ Conventional cervical smear is the widely used cervical cancer screening test in the world. ${ }^{5}$ Cervical atypia in a 
Table 1: Age wise distributions of the subjects with cervical Pap smear findings.

\begin{tabular}{|c|c|c|c|c|c|c|c|}
\hline Age group & $\begin{array}{c}\text { Normal Cytol- } \\
\text { ogy }\end{array}$ & Inflammatory & LSIL & HSIL & Carcinoma & \multicolumn{2}{|c|}{ Total } \\
\hline 21-30 & 252 & 141 & 12 & 2 & 0 & 407 & $27.28 \%$ \\
\hline $31-40$ & 307 & 238 & 21 & 2 & 1 & 569 & $38.14 \%$ \\
\hline $41-50$ & 173 & 106 & 14 & 1 & 1 & 295 & $19.77 \%$ \\
\hline $51-60$ & 126 & 49 & 07 & 1 & 0 & 183 & $12.26 \%$ \\
\hline$>60$ & 30 & 05 & 02 & 1 & 0 & 38 & $2.55 \%$ \\
\hline Total & $888(59.51 \%)$ & $539(36.12 \%)$ & $56(3.75 \%)$ & $07(0.49 \%)$ & $2(0.13 \%)$ & 1492 & 100 \\
\hline
\end{tabular}

cytological smear is categorized as low-grade squamous intraepithelial lesions (LSIL) and high grade intraepithelial lesions (HSIL). LSIL in cytology corresponds with low grade CIN I (cervical intraepithelial neoplasia) where as HSIL corresponds to moderate and severe dysplasia (CIN II and CIN III) in histopathology. ${ }^{6}$ Pap Smear has helped to identified the premalignant lesions of cervix and helped to reduced the mortality rates of cervical cancer in the developed countries. ${ }^{7}$ But pap smear fails to localize the lesion and even though pap smear has become a standard screening test, cervical biopsy remains the 'gold standard' for the diagnosis of precancerous cervical lesion. ${ }^{8}$ The aim of this study was to correlate the changes observed in cervical cytology with cervical biopsy.

\section{MATERIALS AND METHODS}

This was a prospective cross-sectional study done in the Department of Pathology at Nobel Medical College and Teaching Hospital, Biratnagar from January 16, 2017 to January 15, 2018. Permission was obtained from the ethical committee. During this period, all pap smears received in a Department of Pathology were included in the study. However, only cases that had undergone both Pap smear and cervical biopsy were compared. A total 1492 conventional pap smear were received for cytological evaluation. 118 cases underwent both Pap test as well as biopsy. Cervical Smears were stained according to Papanicolaou's method. The cytological interpretation of the smears was made according to the new 2001 Bethesda system. Cervical biopsies were fixed overnight and were processed for paraffin block preparation. Staining was done by Hematoxylin and Eosin stain and was taken for microscopic examination. Microsoft Excel was used for statistical evaluation.

\section{RESULTS}

During the study period, a total of 1492 cervical pap smears were received in the Department of Pathology for an evaluation. Age of the patients ranged from 21 to 68 with majority of belonging to the age group of 31-40 years (Table1). A total of 888 cases (59.51\%) were of normal cytological findings out of which 15 patients underwent biopsy. Inflammation was the next common diagnosis in the
Table 2: Histopathological findings of cervical biopsies

\begin{tabular}{ccc}
\hline Cervical biopsy & Number & Percentage (\%) \\
\hline Normal & 08 & 6.78 \\
Chronic Cervicitis & 78 & 66.10 \\
\hline CIN I & 12 & 10.17 \\
CIN II & 06 & 5.08 \\
\hline CIN III & 07 & 5.93 \\
\hline $\begin{array}{c}\text { Squamous Cell } \\
\text { Carcinoma }\end{array}$ & 05 & 4.24 \\
\hline Adenocarcinoma & 02 & 1.70 \\
\hline Total & $\mathbf{1 1 8}$ & $\mathbf{1 0 0}$ \\
\hline
\end{tabular}

Pap smear (539 cases) out of which 64 patient's underwent biopsy. Cases of Low grade intraepithelial lesion (LSIL) and High grade intraepithelial lesion (HSIL) were 56 and 07 respectively, out of which 30 and 07 patients underwent biopsy. A total of 2 cases were those of Squamous Cell Carcinoma in the Pap smear. Both cases underwent biopsy.

In the biopsy findings, Chronic Cervicitis was the most common case (78 out of 118). A total of 8 biopsies were normal. Cervical intraepithelial neoplasia I (CIN I), CIN II and CIN III cases were 12, 06 and 07 respectively. (Table 2) A total of seven cases were those of malignancies, out of which five were those of Squamous Cell Carcinoma and two were those of Adenocarcinoma.

Among the 15 normal cervical pap smears, 09 showed features of Chronic Cervicitis in a biopsy. Majority (55) of inflammatory smears also showed features of Chronic Cervicitis. However, 02 cases of Adenocarcinoma were diagnosed in a biopsy. Four cases showed CIN I and one case showed features of CIN III in a biopsy. (Table 3) A total of 30 LSIL cases underwent biopsy, out of which 14 showed only inflammation while 08,05 and 03 cases showed features of CIN I, CIN II and CIN III respectively. Out of the 7 HSIL cases of pap smears, 3 were diagnosed as Squamous Cell Carcinoma, which 3 cases were that of CIN III and 1 was that of CIN II, which was statistically significant. Both cases of Squamous Cell Carcinoma (SCC) in Pap smear were confirmed as SCC in a biopsy. 
Table 3: Correlation between cervical cytology and cervical biopsies

\begin{tabular}{ccccccccc}
\hline \multirow{2}{*}{$\begin{array}{c}\text { Cervical Smear } \\
\text { Findings (n) }\end{array}$} & Normal & $\begin{array}{c}\text { Chronic } \\
\text { Cervicitis }\end{array}$ & CIN I & CIN II & CIN III & SCC & Adenocarcinoma & Total \\
\cline { 2 - 11 } Normal(15) & 06 & 09 & 00 & 00 & 00 & 00 & 00 & 15 \\
\hline Inflammatory (64) & 02 & 55 & 04 & 00 & 01 & 00 & 02 & 64 \\
\hline LSIL (30) & 00 & 14 & 08 & 05 & 03 & 00 & 00 & 30 \\
\hline HSIL(07) & 00 & 00 & 00 & 01 & 03 & 03 & 00 & 7 \\
\hline SCC (02) & 00 & 00 & 00 & 00 & 00 & 02 & 00 & 2 \\
\hline Total (118) & $\mathbf{0 8}$ & $\mathbf{7 8}$ & $\mathbf{1 2}$ & $\mathbf{0 6}$ & $\mathbf{0 7}$ & $\mathbf{0 5}$ & $\mathbf{0 2}$ \\
\hline
\end{tabular}

\section{DISCUSSION}

Cervical carcinoma is the second most frequent cancer worldwide, in females. But the invasive cervical carcinoma is considered to be a preventable condition due to its association with a long pre invasive stage (CIN) making it amenable to screening.9 Since 1947, Pap smear has become the main screening tool for the detection of cervical pathology. ${ }^{10}$ The American Cancer Society, National Cancer Institute, American College of Obstetrics and Gynecologists recommend that all sexually active women above the age of 18 years should have annual Pap smear for three consecutive years. In case of three consecutive negative pap smears, the test can be extended for 3- 5 years. ${ }^{11,12}$

This is a prospective cross sectional study carried out in a Department of Pathology, Nobel Medical College from a period of January 16, 2017 to January 15, 2018. A total of 1492 patients were included in a study whose age ranged from 21 to 68 years. Later, 118 patient's cervical biopsies were received for histological evaluation, whose cytological findings were correlated. In a similar study done by Dhakal et $\mathrm{l}^{13}$ and Pradhan et $\mathrm{al}^{14} 75$ and 40 biopsies were compared respectively.

In our study, maximum patients were in between the age group 31 to 40 year (38.14\%) which was similar to the study done by Dhakal et al ( $35.4 \%)^{13}$ and Boicea et al (32.6\%). ${ }^{15}$ In our study, normal smear (59.51\%) was the most common observation in cytological study, followed by inflammatory smear (39.12\%). In a study done by Dhakal et al ${ }^{13}, 67.9 \%$ were normal and $27.9 \%$ were inflammatory smears.

In our study, LSIL and HSIL cases were 3.75\%and 0.49\% respectively which was similar to the study done by Dhakal et $\mathrm{al}^{13}$, but it was very high $(17 \%$ and $12 \%)$ in the study done by Chandrakala et al. ${ }^{16}$ In our study, 9/15(normal pap smear)biopsies revealed features of chronic Cervicitis whereas 2 cases of inflammatory smears in biopsy revealed adenocarcinoma which was same as the study done by Dhakal et al. ${ }^{13}$ In a study done by Vijay et al ${ }^{17}$, a total of 12 cases which were diagnosed as LSIL in pap smear revealed features of carcinoma where as, in our study none of the cases diagnosed as LSIL revealed features of carcinoma.
In the study done by Dhakal et al ${ }^{13}, 5 / 7$ cases diagnosed as HSIL revealed features of CIN III in a biopsy. Rest 2 cases showed features of Squamous cell carcinoma. In our study, out of the 7 HSIL diagnosis of pap smear, 3 showed features of CIN III,3 showed features of squamous cell carcinoma and 1 showed features of CIN II. In both studies, Pap smear was statistically significant in identification of high grade dysplasia and above. A total of 2 cases of squamous cell carcinoma were identified in Pap smear whose diagnosed wasn't changed in a biopsy. Two cases of adenocarcinoma were diagnosed in a biopsy, which was missed in a pap smear. In the study done by Dhakal et $\mathrm{al}^{13}$ one case of adenocarcinoma was identified in a biopsy, which was also missed in a pap smear.

\section{CONCLUSION}

Cervical Pap smear is a very economical and reliable screening test to identify high grade squamous cell lesions and carcinoma, but it fails to localize the lesion and adenocarcinoma is hard to identify in a pap smear. Hence, it should always be done as a routine outpatient screening test as per guideline. But cervical biopsy is the gold standard for its confirmation which should be carried out to confirm the findings of Pap smear and in case of strong clinical suspicion.

\section{Conflict of Interest: None}

\section{REFERENCES}

1. Ferlay J, Soerjomataram I, Dikshit R,et al. Cancer incidence and mortality worldwide: sources, methods and major patterns in GLOBOCAN 2012. Int J Cancer. 2015;136:9. Crossref

2. Aswathy S, Quereshi MA, Kurian B, Leelamoni K. Cervical cancer screening: Current knowledge $\&$ practice among women in a rural population of Kerala, India. Indian J Med Res. 2012;136:205-10. Crossref 
3. Peto J, Gilham C, Fletcher O, Matthews FE. The cervical cancer epidemic that screening has prevented in the UK. Lancet. 2004;364:249-56. Crossref

4. Khan MA RF, Ishfaq G, Tahir F, Subhan F. Pap Smear Screening for Pre-cancerous Conditions of the Cervical Cancer. Pak J Med Res. 2005;44:111-3.

5. Sankaranarayanan R, Budukh AM, Rajkumar R. Effective screening programmes for cervical cancer in low- and middle-income developing countries. Bull World Health Organ. 2001;79:954-62. Crossref

6. Richart RM. A modified terminology for cervical intraepithelial neoplasia. Obstetrics and gynecology. 1990;75:131-3. Crossref

7. Hakama M, Rasanen-Virtanen U. Effect of a mass screening program on the risk of cervical cancer. Am J Epidemiol. 1976;103:512-7. Crossref

8. Rathod GB SD. Histopathological vs cytological findings in cervical lesions (bethesda system)-A comparative study. IAIM. 2015;2:13-6.

9. Ramadevi E MN, Madhavi G B, Sudha Rani V, Padmalatha R, Shamili G. A study of correlation between cytology and histopathology with colposcopic findings Int J Intg Med Sci 2017;4:477-83.

10. Papanicolaou GN TA. The diagnostic value of vaginal smears in carcinoma of the cervix. Am J obs gyn 1941;42:192-206.

11. Mettlin C, Dodd GD. The American Cancer Society Guidelines for the cancer-related checkup: an update. CA Cancer J Clin. 1991;41:279-82. $\underline{\text { Crossref }}$
12. ACOG committee opinion. Routine cancer screening. Number 185, September 1997 (replaces no. 128, October 1993). Committee on Gynecologic Practice. American College of Obstetricians and Gynecologists. International journal of gynaecology and obstetrics: the official organ of the International Federation of Gynaecology and Obstetrics. 1997;59:157-61. Crossref

13. Dhakal R, Makaju R, Sharma S, Bhandari S, Shrestha S, Bastakoti R. Correlation of Cervical Pap Smear with Biopsy in the Lesion of Cervix. Kathmandu Univ Med J. 2016;14:254-7.

14. Pradhan B PS, Mital VP. Correlation of PAP smear findings with clinical findings and cervical biopsy. Kath Univ Med J 2007;5:461-7.

15. Boicea A, Patrascu A, Surlin V, Iliescu D, Schenker M, Chiutu L. Correlations between colposcopy and histologic results from colposcopically directed biopsy in cervical precancerous lesions. Rom J Morphol Embryol. 2012;53:735-41. $\underline{\text { Crossref }}$

16. Chandrakala Joshi PK, Nitya Thakur. Correlation of Pap Smear and Colposcopy in Relation to Histopathological Findings in Detection of Premalignant Lesions of Cervix in A Tertiary Care Centre International Journal of Scientific Study. 2015;3:55-60.

17. Bodal VK, Bal MS, kaur B, Kaur S, Suri AK, Bhagat R, Geetanjali. Correlation of Pap Smear with Histopathological Findings in Malignant and non Malignant Lesions of Cervix. Global Journal of Medical Research 2014;XIV:19-24. 